\title{
REFLEXÕES DE UMA EXPERIÊNCIA ENQUANTO FORMADORA REGIONAL NO CONTEXTO DO PNAIC EM MATO GROSSO
}

\author{
REFLEXIONES DE UNA EXPERIENCIA EN CUANTO FORMADORA REGIONAL EN \\ EL CONTEXTO DEL PNAIC EN MATO GROSSO
}

\author{
REFLECTIONS OF AN EXPERIENCE AS REGIONAL TRAINER IN THE CONTEXT \\ OF PNAIC IN MATO GROSSO
}

Angela Rita Christofolo de MELLO ${ }^{1}$

RESUMO: Este manuscrito socializa aspectos de uma experiência realizada enquanto Formadora Regional do Pacto Nacional pela Alfabetização na Idade Certa, edição final de 2017/2018, coordenado pelo Programa de Pós-graduação em Educação, da Universidade Federal de Mato Grosso, Campus Universitário de Rondonópolis. Os encontros formativos aconteceram no final de 2017 (outubro, novembro e dezembro) em Rondonópolis/MT e início de 2018 (março, abril e maio), em Cuiabá/MT. As análises e reflexões emanam dos excertos autobiográficos selecionados dos relatórios escritos pelos Formadores Locais ao final do último encontro de formação realizado. Estes evidenciam, dentre outros aspectos, que o PNAIC foi uma política que mobilizou conhecimentos alfabetizadores e, com isso, provocou reflexões acerca da necessidade de se repensar o trabalho realizado no ciclo da alfabetização.

PALAVRAS-CHAVE: Formação continuada. Inovação docente. Alfabetização.

RESUMEN: Este manuscrito socializa aspectos de una experiencia realizada como Formadora Regional del Pacto Nacional por la Alfabetización en la Edad Cierta, edición final de 2017/2018, coordinado por el Programa de Postgrado en Educación, de la Universidad Federal de Mato Grosso, Campus Universitario de Rondonópolis. Los encuentros formativos ocurrieron a finales de 2017 (octubre, noviembre y diciembre) en Rondonópolis/MT y principios de 2018 (marzo, abril y mayo), en Cuiabá/MT. Los análisis y reflexiones emanan de los extractos autobiográficos seleccionados de los informes escritos por los Formadores Locales al final del último encuentro de formación realizado. Estos evidencian, entre otros aspectos, que el PNAIC fue una política que movilizó conocimientos alfabetizadores y, con ello, provocó reflexiones acerca de la necesidad de repensar el trabajo realizado en el ciclo de la alfabetización.

PALABRAS CLAVE: Formación continua. Innovación docente. Alfabetización.

ABSTRACT: This manuscript socializes aspects of an experience realized as Regional Trainer of the National Pact for Literacy in the Right Age, final edition of 2017/2018, coordinated by the Postgraduate Program in Education, Federal University of Mato Grosso,

${ }^{1}$ Universidade do Estado de Mato Grosso (UNEMAT), Juara - MT - Brasil. Profa. Adjunta do Campus de Juara, Curso de Pedagogia e Profa. Permanente do PROFLETRAS, Campus de Sinop. ORCID: <http://orcid.org/00000002-9732-6175>. E-mail: angela.mello@unemat.br. 
Campus Universitário de Rondonópolis. The formative meetings took place at the end of 2017 (October, November and December) in Rondonópolis/MT and beginning of 2018 (March, April and May), in Cuiabá/MT. The analyzes and reflections emanate from the autobiographical excerpts selected from the reports written by the Local Trainers at the end of the last training meeting held. These evidences, among other aspects, that the PNAIC was a policy that mobilized literacy knowledge and, with this, provoked reflections about the need to rethink the work carried out in the literacy cycle.

KEYWORDS: Continuing education. Teaching innovation. Literacy.

\section{Introdução}

O Pacto Nacional pela Alfabetização na Idade Certa (PNAIC) formalizou-se entre os governos: federal, do distrito federal, dos estados e municípios brasileiros com a prerrogativa de assegurar a consolidação da alfabetização de todas as crianças até aos oito anos de idade, quando concluem o $3^{\circ}$ ano do Ensino Fundamental. O compromisso efetivou-se no ano de 2013, envolveu todos os entes federados e sua última etapa aconteceu em maio de 2018 em Mato Grosso. Neste Estado, a sua implementação configurou-se na oferta de formação continuada trabalhada pelos Formadores Regionais (FR), junto aos Formadores Locais (FL), e desses junto aos alfabetizadores.

Neste texto socializam-se análises das reflexões emanadas dos relatórios escritos pelos FL ao final do último encontro. Nos relatórios, os FL relataram as experiências vivenciadas no decorrer dos seis encontros que compuseram a última edição do PNAIC no Estado. Complementaram as análises e as reflexões, as experiências vivenciadas enquanto FR. Nas experiências, incluem-se a participação em reuniões de planejamentos, estudos, orientações, realização dos seminários de formações, análises de atividades elaboradas por alfabetizadores, bem como análises de avaliações e relatórios realizados pelos FL. Todas essas ações articuladas ao desdobramento das ações do PNAIC, que em Mato Grosso foram coordenadas por um projeto de extensão vinculado ao Programa de Pós-graduação em Educação (PPGEdu), da Universidade Federal de Mato Grosso, Campus Universitário de Rondonópolis (UFMT/CUR), com vistas à efetivação da Operacionalização da Formação².

2 A “Operacionalização da Formação" é uma estrutura constituída por dois grupos de professores, quais sejam: Formadores e Orientadores de Estudo*. As atividades realizadas por estes grupos incidem sob um terceiro grupo: dos Professores Alfabetizadores, que atuam diretamente com o público alvo desta formação, crianças dos 06 aos 08 anos. Nesta empreitada, as universidades públicas brasileiras que assumiram a coordenação do PNAIC em cada Estado, selecionam os Professores Formadores, por meio de chamada pública. Este profissional realiza a formação dos Orientadores de Estudo. Os municípios parceiros, por sua vez, observam os critérios estabelecidos pelo Ministério Público (MEC) e selecionam os Orientadores de Estudo. Estes OE planejam e trabalham a formação junto aos Professores Alfabetizadores, que atuam no ciclo da alfabetização nas escolas

RIAEE - Revista Ibero-Americana de Estudos em Educação, Araraquara, v. 14, n. 3, p. 1229-1244, jul./set., 2019. e-ISSN: 1982-5587. 
Em setembro de 2018, por meio do processo seletivo referente à Chamada Pública ${ }^{\circ}$ 01/2017/UFMT, constituiu-se a equipe de FR do PNAIC/MT. Em outubro, iniciaram-se as atividades que finalizaram os trabalhos desdobrados dos fundamentos teóricos, conceituais, metodológicos e práticos da última coletânea dos cadernos, editados em 2015, com uma proposta de trabalho interdisciplinar. As três reuniões de planejamentos aconteceram na UFMT/CUR. Esses planejamentos subsidiaram o desdobramento das ações de formação continuada realizadas nos seis seminários. Três seminários aconteceram no campus da UFMT de Rondonópolis, um no campus da UFMT de Cuiabá e dois no Hotel Fazenda Mato Grosso, em Cuiabá/MT. As atividades de encerramento da oferta de formação continuada aconteceram nos dias 09 e 10 de maio de 2018.

A última etapa do PNAIC teve uma configuração diferente das demais, com FR que trabalharam com FL que ofertaram formação aos professores que atuavam no 1, 2 e 3 anos e professores que atuavam na Educação Infantil. Os FR do Novo Mais Educação trabalharam com articuladores e mediadores de aprendizagem das escolas que faziam parte desse Programa. Com isso, em Mato Grosso, constituiu-se uma equipe com FR dos anos iniciais do Ensino Fundamental, da Educação Infantil e do Novo Mais Educação. Os FR trabalharam com turmas com cerca de vinte FL, e a perspectiva de integração curricular, com possibilidade de trabalho articulada as áreas de formação: Linguagem, Matemática, Ciências Humanas e Ciências da Natureza, orientaram as seis etapas de formações realizadas.

Dando continuidade às formações iniciadas em 2015 com os cadernos da coletânea interdisciplinar, no Seminário I, o foco foi o trabalho com a avaliação. A temática foi retomada e trabalhada como necessária em uma perspectiva diagnóstica, processual e formativa no decorrer de todo processo de alfabetização. No Seminário II, retomou-se o caderno V para enfatizar a importância da apropriação dos direitos de aprendizagem vinculados aos eixos da oralidade, leitura/interpretação e escrita no ciclo da alfabetização em todas as áreas do conhecimento. No Seminário III, trabalhou-se o caderno VII que versou sobre a alfabetização matemática na perspectiva do letramento. O caderno VIII, que teve como foco o trabalho com o ensino das Ciências da Natureza no ciclo da alfabetização foi trabalhado no Seminário IV. As Ciências Humanas no ciclo da alfabetização foi o foco de discussão do caderno IX, trabalhado no Seminário V. Na última etapa da formação ofertada

públicas. Assim, Formadores, OE e Alfabetizadores, mobilizam conhecimentos que se materializam em práticas escolares com a intenção de assegurar plena alfabetização junto às crianças matriculadas neste ciclo, em todas as escolas públicas deste País (BRASIL, 2014).

*O PPNAIC, na sua última edição (2017/2018), alterou essa denominação para Formadores Regionais (FG) e Formadores Locais (FL). 
pelo PNAIC, trabalhou-se o caderno 10 que com a temática "Integrando Saberes", retomou e reafirmou a importância de se trabalhar os eixos do processo de alfabetização: leitura/interpretação, escrita/estruturação linguística, produção textual e oralidade de forma integrada aos conhecimentos articulados as diferentes áreas do conhecimento, quais sejam: Linguagem, Ciências da Natureza, Matemática e Ciências Humanas, todas conectadas aos conhecimentos tecnológicos, em atenção à perspectiva dos multiletramentos.

\section{Abordagem metodológica: os excertos autobiográficos com relatos de experiências vivenciadas no contexto do PNAIC em Mato Grosso}

No ano de 2017, o PPGEdu/UFMT/CUR, se manteve na coordenação da formação do PNAIC em Mato Grosso. Essa tarefa envolveu profissionais de Instituições de Ensino Superiores e da Educação Básica, às causas da alfabetização de todas as crianças. As experiências vivenciadas na condição de FR permitiram reunir experiências importantes de serem socializadas, pois emanaram análises reflexivas que poderão contribuir com a avaliação de aspectos desdobrados da referida política do Ministério da Educação (MEC) implementada em Mato Grosso.

O contato com a equipe de coordenadoras do PNAIC em Mato Grosso desde 2013, com os demais colegas formadores e com as turmas de FL, permitiu observações e coletas de informações que influenciaram nas escolhas dos excertos contidos nesse relatório, como também nas suas análises reflexivas. Como afirma Souza (2006), os anseios, os acúmenes e as evidências decorrentes de um processo de formação e auto formação, podem resultar em narrativas autobiográficas concernentes ao desenvolvimento profissional, como também para a avaliação das políticas educacionais disseminadas. Por isso, é importante a publicização de reflexões dessa natureza.

Compreende-se que o conhecimento docente é construído no dia a dia da atuação docente, subsidiado pelas reflexões provindas dos momentos de formação continuada, das observações às experiências dos colegas, como também da troca com os pares, em que professores, individualmente e em grupos, pensam nos processos e nos conteúdos dessa construção. Os excertos autobiográficos contidos no item que segue, foram retirados dos relatórios elaborados pelos formadores locais ao final da última edição do PNAIC/2017/2018, e são resultantes destas reflexões. 


\section{A formação ofertada no contexto do PNAIC em Mato Grosso: as vozes dos formadores locais}

O Pacto Nacional pela Alfabetização na Idade Certa (PNAIC) reeditou em 2017 o compromisso assumido em 2013 ao sustentar que o principal objetivo do Programa decorre da luta para assegurar a consolidação da alfabetização a todas as crianças brasileiras, ao final do terceiro ano do Ensino Fundamental. Assim, o conjunto de ações organizadas pelas autoridades que pensaram o Programa em 2013, as quais incluiu o aperfeiçoamento profissional de todos os professores que atuavam no ciclo da alfabetização, por meio da oferta de formação continuada, teve continuidade em 2014, 2015, 2016 e 2017/2018. Esta formação foi subsidiada pelo MEC que disponibilizou recursos bibliográficos como as coletâneas de cadernos distribuídas aos segmentos vinculados à formação. No ano de 2013 - Língua Portuguesa, em 2014 - Matemática, em 2015 - Interdisciplinaridade, e demais materiais didáticos pedagógicos (BRASIL, 2014).

Subsidiaram os seis seminários de formação da última edição do PNAIC/2017/2018, três reuniões de planejamentos coordenadas pelo PPGEdu/UFMT/CUR. As fundamentações teóricas, recursos e estratégias didáticas discutidas e selecionadas nas reuniões de planejamentos demarcaram o desenvolvimento dos trabalhos realizados junto aos FL. Esse trabalho pautou-se na articulação entre as áreas do conhecimento e o processo de alfabetização. Desse modo, em todos os seminários foi reforçada a necessidade de reflexões atinentes a um processo de alfabetização que tenha como matéria prima os diversos gêneros textuais e suas funções sociais para se trabalhar todos os direitos de aprendizagem desse ciclo.

\section{Intempéries da política de formação ofertada no âmbito do PNAIC/MT}

Nesse trabalho, levaram-se em consideração as orientações contidas no Caderno de Apresentação do PNAIC, de que as coletâneas foram elaboradas com uma estrutura adequada para auxiliar o trabalho dos FR, dos FL e dos Professores Alfabetizadores:

[...] sem, no entanto, constituir-se como uma amarra. Dessa maneira, por exemplo, apesar de sempre haver sugestões para os encontros em grupo, deve-se entender que outros caminhos, ditados pelas experiências e conhecimentos de cada grupo, podem e necessitam ser seguidos (BRASIL, 2014, p. 13).

Esta recomendação enriqueceu o trabalho realizado. As experiências socializadas, tanto pela FR, como pelos FL, contribuíram para a compreensão dos conceitos explorados nos cadernos. Também as avaliações realizadas ao final de cada seminário pelos FL apresentaram 
diagnósticos que sinalizaram aspectos que precisavam ser repensados para os seminários posteriores.

Todavia, apesar de todo esforço, um problema recorrente em todos os seminários foi a densidade das atividades planejadas e o tempo insuficiente para trabalhá-las. As orientações contidas no Caderno de Apresentação do PNAIC (2014) explicitavam que o conjunto de textos disponibilizados no item "Aprofundando o Tema" além de trazer o aprofundamento teórico conceitual necessário para a formação do alfabetizador, fora organizado de forma a permitir diversos debates e reflexões sobre o assunto abordado, dinâmica importante, mas que demandava tempo. Todavia, prevendo o pouco tempo para a realização dos seminários de formação com a abordagem dos textos referenciados nos cadernos, recomendava-se que na medida do possível fossem:

[...] lidos fora do tempo e espaço dos encontros de formação. Nesses encontros, cabe a apresentação elou discussão coletiva das ideias principais de todos ou alguns desses textos. É importante salientar que, por vezes, esses textos apresentam informações para além dos conceitos que devem ser trabalhados em sala de aula, ampliando e aprofundando o repertório matemático do professor alfabetizador. (BRASIL, 2014, p. 07 - grifo nosso).

Esta recomendação infelizmente não aconteceu. Segundo os FL, devido às muitas atribuições assumidas em decorrências das funções que exerciam para além desta. Observouse que muitos FL liam o texto pela primeira vez durante a realização dos seminários. Essa realidade não foi diferente em relação aos alfabetizadores, que, segundo afirmação dos FL, também chegavam à formação sem a leitura preliminar dos textos disponibilizados nos cadernos.

A coletânea de Cadernos Interdisciplinares editados em 2015, constituída de dez cadernos, foi dividida para que os direitos de aprendizagem das áreas de Linguagem, Matemática, Ciências da Natureza e Ciências Humanas fossem trabalhados de forma integrada e articulada ao processo de alfabetização. Todavia, em 2015 o Programa, de certa forma, perdeu força e a sua manutenção até o encerramento dos trabalhos em maio de 2018, foi permeada por conflituosas resistências que foram demarcadas com interrupções e retomadas, geralmente nos últimos meses dos anos de 2015, 2016 e 2017. Essa realidade prejudicou o desenvolvimento da política, como evidência o excerto destacado:

Infelizmente, não podemos deixar de abordar os pontos negativos que tivemos no decorrer desta caminhada. Por indecisões políticas, vários fatos aconteceram e através dos mesmos podemos perceber certo descaso com a área educacional. Um destes que podemos destacar com precisão foi o período em que os Seminários iniciaram já no encerramento do ano letivo 
2017. [...] neste período é tudo muito corrido, pois estamos encerrando o ano letivo, os professores estão acarretados de compromissos com avaliações, diários, relatórios e reuniões de encerramento, [...]. Tudo isso acaba prejudicando $\mathrm{o}$ andamento das formações que precisamos trabalhar posteriormente aos seminários, sendo assim os estudos já não tiveram o mesmo aproveitamento, pois o tempo se tornou escasso (Relatório FL-MDL, maio de 2018).

De fato, os aspectos elencados por essa FL interferiram qualitativamente nas formações realizadas. O contexto reportar-se as afirmações de Tardif (2014, p. 114-115), para o referido autor, atualmente "exige-se, cada vez mais, que os professores se tornem profissionais da pedagogia, capazes de lidar com inúmeros desafios suscitados pela escolarização de massa em todos os níveis do sistema de ensino". Todavia, ressalta o autor, para que os processos de formação continuada surtam efeitos, precisam estar em sintonia com o concreto processo de trabalho e realidade dos professores.

Dentre outros aspectos relevantes contidos nos relatórios, destacou-se o descompromisso por parte da Secretaria de Estado de Educação (SEDUC/MT) que em 2017/2018 não cumpriu em muitos aspectos a parceria firmada junto ao MEC. Essa situação impossibilitou a participação de muitos FL nos seminários e, consequentemente, na formação realizada in loco. Nos Seminários II e III a vinda dos FL foi proibida pela SEDUC/MT. Já nos Seminários IV, V e VI essa Secretaria não impediu a participação, mas também não custeou a vinda dos FL, como destacou o excerto:

[...] só conseguimos participar porque custeamos nossas próprias despesas, e contamos com apoio de colegas em Cuiabá para hospedagem, visto não termos tido respaldo financeiro, e/ou ajuda de custo para tal, por parte da Secretaria de Educação do Estado - SEDUC/MT, que deixou livre a participação (Relatório, FL-ZOS, maio de 2018).

A postura da SEDUC/MT de se retirar do Programa, comprometeu o trabalho e decepcionou não apenas a coordenação geral de formação do PNAIC, os FR, como também os FL, como se observa no excerto que segue: "Fiquei decepcionado [...] a meu ver fomos prejudicados, ou seja, ficamos fora de três, dos seis Seminários presenciais, [...] realizamos algumas atividades à distância. Mas não foi a mesma coisa, pois sem aquele momento de trocas de experiências a formação fica comprometida" (Relatório, FL-MRO, maio de 2018). Por tudo isso, Tardif (2014, p. 115) adverte que é imperativo que ao se estudar e se analisar aspectos inerentes à docência, que este "seja sempre situado no contexto mais amplo da análise do trabalho do professor". Seria desumano falar de trabalho docente, sem incluir o atual contexto educacional em que as políticas públicas são disseminadas. 
Foram muitas as circunstâncias desfavoráveis que prejudicaram o desdobramento dessa política nos últimos três anos. O excerto que segue, apresenta uma síntese desse contexto:

\begin{abstract}
A falta de material impresso que tivemos nestes últimos seminários também foi péssima, pois nem sempre as escolas disponibilizaram a impressão dos cadernos para todos os docentes. O prazo curto para preparação dos encontros também atropelou as formações e influenciou no resultado final das mesmas. [...] O corte das bolsas desmotivou bastante os nossos docentes, que muitas vezes se reuniram após suas jornadas de trabalho, o que nem sempre os deixaram satisfeitos. $\mathrm{O}$ incentivo das bolsas era um meio de fazer com que a participação se tornasse mais agradável (Relatório FL-MDL, maio de 2018).
\end{abstract}

Há nos relatórios finais escritos pelos FL vários aspectos negativos que de fato, impactaram de forma indesejada no resultado da política, como demonstraram os excertos acima selecionados. Contudo, vários aspectos positivos descritos nos referidos relatórios, de certa forma, sobrepuseram-se aos eventos que prejudicaram que as metas estabelecidas fossem alcançadas. Alguns desses aspectos estão destacados no próximo subitem. Como afirma Frigotto (2010, p. 168) "negatividade e positividade, todavia, teimam em coexistir numa mesma totalidade e num mesmo processo histórico e sua definição se dá pela correlação de força dos diferentes grupos e classes sociais". Na compreensão do referido autor, essas relações decorrem porque conflitam necessidades humanas que são antagônicas a reprodução do capital.

\title{
Calenturas da política de formação continuada ofertada no âmbito do PNAIC/MT
}

A configuração do PNAIC lançado em Mato Grosso no início de 2013 tinha uma operacionalização de formação que atendia, de forma mais objetiva, as expectativas dos diversos perfis envolvidos nessa empreitada. No ano de 2014, essa condição foi mantida, todavia em 2015 a política perdeu força e a formação pensada para esse ano, foi concluída apenas em maio de 2018. Essa conclusão foi viabilizada, em grande parte, pela persistência e insistência de expressivo percentual de todos os perfis envolvidos, que valorizou a política e não mediu esforços para seguir firme até o final dos trabalhos reservados aos cadernos editados em 2015.

O excerto selecionado a seguir, reedita as reflexões acima e denota que muitos aspectos impulsionaram a persistência pela continuidade do PNAIC, uma delas foi a 
compreensão de que a formação continuada é um direito e uma necessidade de todos os professores. Assim,

[...] como tudo na vida é um processo, acredito que avancei bastante nesse processo de ensinar-aprender, porém isso não aconteceu no primeiro ano apenas, mas ao longo desses seis anos consecutivos. O processo é lento, mas é satisfatório quando se chega a certo nível de compreensão do mesmo (Relatório, FL-DFF, maio de 2018).

A contribuição da FL imprime que a oferta da formação continuada se justifica em decorrência da necessidade que os professores têm de atualização profissional que lhes permitam avaliar, refletir e inovar a sua atuação docente. $\mathrm{O}$ reconhecimento dessa necessidade por parte dos FL foi mais um aspectos importante que favoreceu a persistência na continuidade da política, como se pode observar no excerto a seguir: "O PNAIC forneceu importantes subsídios teóricos e metodológicos, conhecimentos didáticos, e oportunizou experiências pedagógicas exitosas para a nossa formação, bem como para os alfabetizadores das escolas atendidas, contribuindo para com a melhoria da prática docente" (Relatório, FLZOS, maio de 2018). Essas contribuições remetem a Ghedin (2012, p. 165) ao se referir à formação continuada de professores, segundo ele:

Não há conhecimento pronto e acabado, do mesmo modo que não há vida absoluta. Tudo é processo contínuo de construção e de autoconstrução. Olhar o que estamos fazendo, refletir sobre os sentidos e os significados do fazer pedagógico é, antes de tudo, um profundo e rigoroso exercício de compreensão do próprio ser.

Neste sentido, pode-se afirmar que a formação ofertada no contexto do PNAIC, reiterou que a apropriação de novos conhecimentos é um exercício político continuado que emerge transformações e mudanças de atitudes por meio da efetiva participação e envolvimento dos docentes em processos formativos.

Outro fator que preponderou na efetiva participação dos FL até o último encontro, apesar da conflituosa conjuntura que não propiciou condições de participação para muitos, se deve as formações ofertadas:

Muitas vezes pensei em desistir do Programa. Felizmente a cada seminário que participava em Cuiabá fui ganhando confiança, acreditando cada vez mais na proposta de ensino oferecida nas formações, onde me proporcionou melhores esclarecimentos de planejamento, principalmente em entender o currículo no ciclo da alfabetização e seus princípios gerais, os conceitos de alfabetização e letramento e o que ensinar neste Ciclo (Relatório, FL-EDPA, maio de 2018). 
O depoimento da FL evidência que a formação ofertada no contexto do PNAIC, provocou nos FL reflexão, exercício importante e necessário para a mudança da prática docente. Como afirma Valadares (2012, p. 217):

As reflexões na ação consistem em um diálogo com a situação, no exato momento em que os imprevisíveis e incertos fenômenos são encontrados. Sob esta ótica, os problemas não são moldados e estabelecidos de uma perspectiva externa, sendo posteriormente acompanhado de uma análise que o prático realiza sobre os processos de sua atuação, ou seja, de uma reflexão sobre a ação.

Ainda sobre o reconhecimento do trabalho realizado nos Seminários formativos, uma formadora afirmou que:

Com toda certeza os encontros de formação têm me possibilitado uma maior segurança/confiança para com as temáticas apresentadas no decorrer nas unidades trabalhadas. As sugestões pronunciadas pela nossa Formadora Regional nos transmite uma garantia de que não estamos sozinhos nessa jornada, fato que realmente tem se concretizado a cada unidade, na medida em que as incertezas e as inseguranças vão surgindo, entro em contado com a Formadora por diversos meios de comunicação e sou prontamente atendida e esclarecida nos meus anseios (Relatório, FL-SMPS).

Como mostram as contribuições, inúmeros aspectos positivos mobilizaram a efetiva participação dos FL nos Seminários. Dentre estes se destacou o insistente exercício do aprofundamento teórico, conceitual e metodológico como condição para a renovação e inovação da atuação em sala, como demonstra o excerto selecionado: “[...], a junção da teoria e prática trabalhada pela formadora por meio dos textos teóricos, articulados aos relatos de experiências contidos nos cadernos do PNAIC, provocou constantes reflexões acerca da necessidade de inovação e mudança pedagógica” (Relatório, FL-HSR, maio de 2018).

O reconhecimento e a valorização da fundamentação teórica trabalhada no decorrer dos Seminários de formação, ressaltada nos relatórios escritos pelos FL, reportam-se as afirmações de Pimenta (2012, p. 31), segundo ela:

[...] a teoria como cultura objetivada é importante na formação docente, uma vez que, além de seu poder formativo, dota os sujeitos de pontos de vista variados para uma ação contextualizada. Os saberes teóricos propositivos se articulam, pois, aos saberes da prática, ao mesmo tempo ressignificando-os e sendo por eles ressignificados. O papel da teoria é oferecer aos professores perspectivas de análise para compreenderem os contextos históricos, sociais, culturais, organizacionais e de si mesmos como profissionais, nos quais se dá sua atividade docente, para neles intervir, transformando-os.

Como afirmou uma FL no relatório escrito em maio de 2018, a formação trabalhada no âmbito do PNAIC possibilitou reflexão sobre as práticas cotidianas dos professores 
alfabetizadores, e, com isso, ressaltou a necessidade de um trabalho docente dinâmico, inovador e interativo em atenção às peculiaridades do processo de alfabetização. Diante disso, pode-se afirmar que a formação ofertada atendeu suas prerrogativas, pois como se recomenda:

A formação terá como base uma reflexão dos sujeitos sobre sua prática docente, de modo a permitir que examinem suas teorias implícitas, seus esquemas de funcionamento, suas atitudes etc., realizando um processo constante de auto avaliação que oriente seu trabalho. A orientação para esse processo de reflexão exige uma proposta crítica da intervenção educativa, uma análise da prática do ponto de vista dos pressupostos ideológicos e comportamentais subjacentes (IMBERNÓN, 2001 p. 48-49).

Outro aspecto ressaltado por todos os FL como positivo foram as trocas de experiências e as socializações das boas práticas desenvolvidas, tanto nos momentos de formações, como no interior das salas de aulas pelos alfabetizadores, como destacou uma FL:

A troca de experiência e o trabalho em equipe vêm somar, [...] muitos educadores colocam em prática o que aprenderam nas formações, os educandos estão aprendendo de forma mais sistemática e articulada e com qualidade. Aprendi muito com os relatos de práticas reais, nos quais também pude rever minhas próprias práticas. Tive a oportunidade de me apropriar e aprofundar em novos conceitos (Relatório, FL-JTDM, maio de 2018).

Como afirma Vygostky (1989), a experiência individual pode ser ampliada com a experiência do grupo, o que ampliará os conhecimentos atinentes à docência, e, com isso, melhorar sobremaneira a qualidade da educação ofertada. Contudo, as contribuições descritas nesse item conferem como afirma Pimenta (2012, p. 44), que de fato:

A educação é um fenômeno complexo, porque histórico. Ou seja, é produto do trabalho de seres humanos e, como tal, responde aos desafios que diferentes contextos políticos e sociais lhe colocam. A educação retrata e reproduz a sociedade; mas também projeta a sociedade que se quer. Por isso, vincula-se profundamente ao processo civilizatório e humano. Enquanto prática histórica tem o desafio de responder às demandas que os contextos lhe colocam.

Outro aspecto positivo a ressaltar é o reconhecimento, da boa qualidade da fundamentação teórica contida nos cadernos do PNAIC, na seção "Aprofundando o Tema", articulada a possibilidades de atividades práticas, com inúmeras sugestões de sequências didáticas e sequências de atividades, como demonstra o excerto:

[...] os conteúdos abordados nos cadernos de estudos, os mesmos trazem ótimas teorias, sugestões de trabalho em sala de aula, com muita reflexão sobre a prática pedagógica, ajuda-nos a propor ao professor a planejar suas aulas de forma mais dinâmicas, como também nós formadores e alfabetizadores a ler muito, já que com tantos afazeres, não temos muito 
tempo para dedicar as leituras no dia a dia (Relatório, FL-VSO, maio de 2018).

Segundo Gimeno (1999), teoria e prática são inseparáveis e a epistemologia da prática consolida-se mediante essa indissociabilidade. Mesmo porque,

o conhecimento docente não é formado apenas na experiência concreta do sujeito em particular, podendo ser nutrido pela 'cultura objetiva' (as teorias da educação, no caso), possibilitando ao professor criar seus 'esquemas' que mobiliza em suas situações concretas, configurando seu acervo de experiência 'teórico-prático' em constante processo de reelaboração (PIMENTA, 2012, p. 31).

Neste sentido, todos os FL afirmaram que a fundamentação teórica trabalhada na formação ofertada no âmbito do PNAIC contribuiu com reflexões atinentes ao planejamento de intervenções docentes diferenciadas que foram incorporadas a prática do professor, como demonstra o excerto:

[...] as experiências vividas e as orientações recebidas farão parte da nossa prática na sala de aula e na nossa vida, foi um estudo muito bom, com uma metodologia prazerosa. Nunca mais serei a mesma depois desse curso, me ajudou muito, tanto profissional, quanto pessoal, acho que nenhuma formação pedagógica nos ensinou tanto como nesses anos de PNAIC (Relatório, FL-VSO, maio de 2018).

As reflexões da FL justificam porque Pimenta (2012, p. 25) afirma que a formação continuada "ganhou força" nos últimos anos, haja vista que, por meio da sua oferta, "as demandas da prática, bem como as necessidades dos professores" frente aos conflitos e dilemas de sua atividade, podem ser superadas. (Grifo nosso).

Outro aspecto destacado em todos os relatórios escritos pelos FL ao final da última edição do PNAIC foi a conclamação para a continuidade da política. Todos destacaram o mérito dessa política que ofertou formação continuada pautada em uma fundamentação teórica articulada à realidade educacional, com inúmeros relatos de intervenções realizadas por professores alfabetizadores que reconheceram que mudar a prática docente em atenção à oferta de uma alfabetização na perspectiva do letramento, é possível. Neste sentido, a formação trabalhada:

[...] serviu para fortalecer o debate da compreensão da necessidade de seguirmos em nossos estudos, seja nas escolas, seja por meio da solicitação de novas Políticas de Formação que almejam nossos alfabetizadores, que nos externalizaram em seus depoimentos. Muitos relataram que esta foi a primeira oportunidade que tiveram de participar de um Programa Federal com a estrutura e discussão teórica/prática proporcionada por este Curso. 
Destacamos o desejo de todos, de que haja a continuidade dessa formação (Relatório, FL-GLR, maio de 2018).

O excerto que segue, foi selecionado porque reedita o conteúdo desse item, ou seja, apesar de todos os contrapontos vivenciados no decorrer dos seis anos de PNAIC em Mato Grosso, os aspectos positivos dessa política ofuscam os negativos:

[...] me orgulho em relatar que os aspectos positivos superaram os negativos. Pontos positivos como todos os assuntos tratados, desde a carga horária, com metodologias, textos, trocas de experiências e discussões realizadas no decorrer dos encontros foram de grande relevância para os nossos conhecimentos, tanto enquanto formadora, como professores alfabetizadores, conhecimento estes que foram pautados pelo compromisso de crescimento pessoal, cultural e profissional. Vejo que nós professores temos necessidade de atualização teórico/metodológica para alicerçar nossas práticas em sala de aula. Diante disso, vejo nas formações do PNAIC uma forma de refletir e promover mudanças pessoais e profissionais.

Os excertos selecionados confirmam que de fato a formação continuada se justifica porque é amplamente reconhecida como uma necessidade ao exercício pleno da docência. Como afirmam vários pesquisadores do tema em questão, na hodiernidade, a inserção de todos os educadores em processos de formação continuada é condição para a sua atualização profissional. A ausência da atualização profissional implica na oferta de uma educação que poderá não atender aos anseios e as perspectivas dos estudantes diante do avanço científico e tecnológico que impõe a todos os seres humanos, perspicácia, inovação, criatividade, bem como domínio de conhecimentos amplos e complexos. Neste contexto, a consolidação da apropriação do Sistema de Escrita Alfabético, é condição primeira, por isso as ações de formação continuada ofertadas no âmbito do PNAIC, analisadas neste texto, ganharam corpo e se sustentaram no decorrer dos seis últimos anos, apesar de todas as intempéries vivenciadas.

\section{Considerações finais}

Nos seis seminários realizados, três ao final de 2017 e três no início de 2018 , seguiu-se uma rotina com o desdobramento dos textos da seção aprofundando o tema dos cadernos trabalhados. As leituras deleites, bem como a utilização dos demais materiais pedagógicos disponibilizados pelo MEC, subsidiaram as temáticas abordadas. O chamamento para a importância da utilização das obras pedagógicas indicadas como complementares aos livros didáticos, aos acervos de dicionários de Língua Portuguesa, aos jogos pedagógicos de apoio à alfabetização, às obras de referências, como também às de literatura, de pesquisa e de apoio 
pedagógico aos professores foram recorrentes em todos os seminários. Os materiais como os jogos e softwares de apoio à alfabetização e demais recursos foram indicados e também utilizados nos seminários, a partir de diferentes estratégias didáticas.

As leituras complementares sugeridas ao final de cada caderno da coletânea do PNAIC de 2015 "Para Saber Mais" também foram comentadas e sugeridas em muitas situações em que os FL manifestaram dúvidas em relação aos conceitos abordados. Assim como os diversos vídeos e sites indicados para pesquisa.

A recomendação de elaboração de planejamentos simples e com importantes retornos pedagógicos, foi reafirmada em diversos momentos das formações. Como orientavam os fundamentos contidos nos cadernos "é importante salientar que não há necessidade de atividades sofisticadas e que demandem um excessivo tempo do professor para seu planejamento e execução" (BRASIL, 2014, p. 25), mesmo porque, "atividades simples possuem grande potencial pedagógico desde que contribuam para aproximar situações do cotidiano a situações da sala de aula" (Idem). Desse modo, também foi orientada a valorização dos recursos que se encontravam disponíveis nas escolas. Como também, a adoção de planejamentos concatenados aos eixos do processo de alfabetização e aos direitos de aprendizagem de todas as áreas do conhecimento.

As experiências vivenciadas enquanto FR nos anos de 2014, 2016, 2017 e 2018 permitiram reeditar a necessidade da oferta de formação continuada a todos os professores alfabetizadores. A melhoria da qualidade da educação demanda tempo e persistente oferta de formação continuada. O professor precisa refletir e acomodar os fundamentos teóricos, conceituais, metodológicos e práticos trabalhados nos encontros formativos, e estas reflexões pedem amadurecimento interventivo. Isso porque, a insegurança de abrir mão do que habitualmente faz no interior de uma sala de aula, pode levar o alfabetizador a resistir às inovações pedagógicas sugeridas na formação continuada ofertada no âmbito do PNAIC.

Pondera-se ao concluir o relatório que o campo da atuação docente é delicado, pois são muitos os fatores que atravessam a formação, tanto inicial, como continuada do educador, como afirmam Ferreira e Leal (2010). Dentre esses fatores listam-se: a sobrecarga de trabalho dos profissionais da educação; as lacunas decorrentes da formação inicial; a política de atribuição de aulas; as muitas atribuições dos profissionais da educação, nas quais se incluem elaboração de relatórios, planejamentos, preparação de recursos didáticos, reuniões pedagógicas e administrativas, a descontinuidade das políticas educacionais, a ausência de um sistema de educação de referência aos níveis e modalidades educativas, etc. 
Todavia, apesar dos limites decorrentes da implementação de políticas públicas educacionais, a oferta de formação continuada sistematicamente planejada, ancorada em estudos aprofundados de pesquisadores do tema em questão, poderá desvelar as ideologias decorrentes dessas políticas, como também favorecer a superação dos seus limites.

\section{REFERÊNCIAS}

BRASIL. Ministério da Educação. Secretaria de Educação Básica. Diretoria de Apoio a Gestão Educacional. Pacto Nacional Pela Alfabetização na Idade Certa: Formação do Professor Alfabetizador, Caderno de Apresentação. Brasília: 2012.

BRASIL. Ministério da Educação. Secretaria de Educação Básica. Diretoria de Apoio a Gestão Educacional. Pacto Nacional Pela Alfabetização na Idade Certa: apresentação, Alfabetização Matemática. Brasília: 2014.

FERREIRA, Andrea. T. B.; LEAL, T. F. A formação continuada de professores: enfim o que pensam e sugerem os docentes? In: Formação continuada de professores: Reflexões sobre a prática. Recife: Editora Universitária, UFPE, 2010.

FRIGOTTO, G. Educação e a crise do capital real. 6. ed. São Paulo: Cortez, 2010.

GHEDIN, E. Professor Reflexivo: da alienação da técnica à autonomia da crítica. In: PIMENTA, Selma Garrido e GHEDIN, Evandro (Orgs.). Professor Reflexivo no Brasil: gênese e crítica de um conceito. 7 ed. São Paulo: Cortez, 2012.

GIMENO SACRISTÁN, J. Poderes instáveis em educação. Porto Alegre: Artes Médicas, 1999.

IMBERNÓN, F. Formação docente e profissional: formar-se para a mudança e a incerteza. São Paulo: Cortez, 2001.

PIMENTA, Selma Garrido. Professo Reflexivo: construindo uma crítica. In: PIMENTA, Selma Garrido e GHEDIN, Evandro (Orgs.). Professor Reflexivo no Brasil: gênese e crítica de um conceito. 7 ed. São Paulo: Cortez, 2012.

SOUZA, E. C. A arte de contar e trocar experiências: reflexões teórico-metodológicas sobre história de vida em formação. In: Revista educação em questão. v. 25, n. 11, 2006, jan./abr., p. 22-39, Natal, RN: EDUFRN. Disponível em:

http://www.revistaeduquestao.educ.ufrn.br/pdfs/v25n11.pdf. Acesso: 15 abr. 2015.

TARDIF, M. Saberes docentes e formação profissional. 17 ed. Petrópolis, RJ: Vozes, 2014.

VALANDARES, J. M. O professor diante do espelho: reflexões sobre o conceito de professor reflexivo. In.: PIMENTA, Selma Garrido e GHEDIN, Evandro (Orgs.). Professor Reflexivo no Brasil: gênese e crítica de um conceito. 7 ed. São Paulo: Cortez, 2012. 
VYGOTSKY, L. S. A formação social da mente: o desenvolvimento dos processos psicológicos superiores. 3. ed. São Paulo: Martins Fontes, 1989.

\section{Como referenciar este artigo}

MELLO, Ângela Rita Christofolo de. Reflexões de uma experiência enquanto formadora regional no contexto do Pnaic em Mato Grosso. Revista Ibero-Americana de Estudos em Educação, Araraquara, v. 14, n. 3, p. 1229-1244, jul./set., 2019. e-ISSN: 1982-5587. DOI: 10.21723/riaee.v14i3.11510

Data de Submissão: $26 / 06 / 2018$

Revisões Requeridas: 30/09/2018

Aceite em: 04/11/2018

Publicado em: 11/05/2018 